\title{
Of course! We MUST look at the Arts... in its widest sense!
}

Saroj Jayasinghe

I am delighted to read the opinions expressed by Harindra Karunatilake and Vajira Dharmawardene in their paper on "Perhaps you should look at Art". In the next few paragraphs I wish to share our experiences and narrate a story from Colombo!

The arts (including poetry, music, dance, photography and paintings) are powerful mediums to express and show the human condition, the suffering of patients, and even the process of dying. The University of Colombo recognized the importance of humanities in health by establishing in 2016, the first Department of Medical Humanities in Sri Lanka, and perhaps the first in the region.

In order to capture the wide range of disciplines that contribute towards Medical Humanities, we defined it as "the use of humanities to improve well-being and achieve goals in health professional education". It is an interdisciplinary field which draws on the creative and intellectual strengths of diverse disciplines related to the humanities, including literature, art, creative writing, drama, film, music, philosophy, ethical decision making, anthropology, and history. Its main pursuits are to improve health care (e.g. by having more compassionate health professionals, more aesthetic health care facilities that promote healing, and the use of arts as forms of therapies) and to achieve goals in health professional education (e.g. attempts to teach humaneness, and use arts to improve teaching/learning). A pioneer in the latter was Nimal Senanayake Emeritus Professor of Medicine in Peradeniya, who has written several film scripts that focus on mental illness and neurological disorders such as epilepsy. Another significant and related event in terms of research was the oration of the Kandy Society of Medicine 2011 delivered by Dr Shavindra Dias from the University of Peradeniya, on "Portrayal of mental illnesses in Sinhalese films; what is shown and what is meant".

Some of the seeds of humanities were sowed in the Faculty of Medicine, Colombo around 1974, when an Arts Circle was officially formed. There was a cultural renaissance in our midst, probably because the district quota enables a wider spectrum of students to enter the Faculties of

\section{Chair Professor of Medicine}

Founder Head, Department of Medical Humanities, Faculty of Medicine, University of Colombo.
Medicine. For the first time we produced several plays in Sinhala and Tamil, and invited legends in the local music scene for recitals (e.g. Pandith Amaradeva and Nanda Malini). A few students held public art exhibitions, in well-known art galleries ("Asymmetric Waves' at the Lionel Wendt by J Withana and S Jayasinghe).

The Arts Circle and its activities was a significant cultural development in the Faculty, as they developed 'outside' traditional student societies that were dedicated more towards religious ceremonies and festivals. They also celebrated indigenous culture and the arts, and introduced enjoyment of this facet to the students. Over a few decades, this amateur student circle evolved to its present form of excellence. It is now a pathway to demonstrate the talents of our students and they conduct concerts that compete with standards, levels of skills, and creativity of professionals in the field of music and plays (e.g. 'Nin-naada'). Similar levels of excellence in expression are seen with the photographic society, student artists, and other student groups.

It is in this environment that a more formal introduction of humanities in the medical curriculum began. One of the first steps was in 2012, with the commencement of a lecture in the Behavioural Sciences Stream to 4th year medical students on "Illness from the perspective of humanities". It showed examples from photography, posters, art, poems, music, videos and films that helped to understand illness, death and the human condition. The examples were mainly from Sri Lanka: The story of the diagnosis of cancer of colon in Henry Jayasena, the famous actor, and students are directed to read extracts from his book titled "Balha Gilano - the story of a cancer patient"; The paintings by Sujith Rathnayake are shown to demonstrate the suffering of post-trauma flashbacks he had after the tsunami; The film 'Sawara' (Seven Notes) is briefly described, to illustrate the traumatic journeys of persons infected with HIV in Sri Lanka. This was complemented by descriptions of art by Pablo Picasso (e.g. 'The mad man'), and Van Gogh (e.g. selfportrait with the ear cut off). Since the introduction of this lecture, a handful of students have done electives on areas related to humanities (e.g. 'The depiction of illness in films'). 
After the establishment of the Department, and during 2016-2017 the Faculty organized a series of guest lectures on topics relating to aesthetics in medicine by notable academics (e.g. 'Role of arts in medicine' by Professor Carlo Fonseka, Chairman Sri Lanka Medical Council, 'Approaches to teaching humanities to medical students' by Professor Anoja Fernando, Emeritus Professor from University of Ruhuna, 'Using poetry to inculcate attitudes' Prof Narada Warnasuriya Senior Professor from Kothalwala Defence University, 'Humanities in medicine: The Ruhuna experiment' by Professor Susirith
Mendis, former Vice Chancellor from Ruhuna). This has enabled us to develop a teaching programme in medical humanities as part of the Behavioural Science Stream in the Faculty of Medicine, Colombo. Thus, in our own small way we have begun our journey to 'look at the Arts' as proposed by the authors!

We invite all interested to join us in this venture to improve healthcare and standards of education....Please drop an email to us on medicalhumanities@med.cmb. ac.lk 